\title{
Analysis of secondary market policies of radio frequency spectrum in indonesia
}

\author{
Gunawan Wibisono $^{1^{*}}$, Isnur Widaryanto ${ }^{2}$, and Cahyo Nugroho ${ }^{1}$ \\ ${ }^{1}$ Department of Electrical Engineering, Universitas Indonesia, Kampus Baru UI, 16424 \\ ${ }^{2}$ Ministry of Communication and Informatics, Republik Indonesia, Jakarta, INDONESIA
}

\begin{abstract}
The radio frequency spectrum is an important factor in improving service quality and expanding the network of cellular operators. Operators attempt to obtain additional spectrum allocations through the practice of merging or taking over the radio spectrum, where the process is dependent on ministerial approval. In Indonesia, its implementation produces different treatment in terms of the use of radio frequency spectrum, some are accompanied by divestment another are not. This process is not through the mechanism of the secondary market spectrum. Based on the practice of secondary market spectrum in other countries, it provides business certainty to operators and gives maximum value in the spectrum. In this research, secondary market policy for Indonesia is proposed, where evaluation and analysis will be done using regulation impact analysis (RIA). Three proposed secondary market alternatives include to keep current conditions (alternative 1), secondary market mechanism with direct trading (alternative 2), and broker mechanism with independent supervision (alternative 3). Assessment will be done using cost base analysis (CBA) based on plus minus implications (PMI), and decision will be made based on multi criteria analysis (MCA). According RIA based analysis, the results obtained that alternative 3 provides many advantages compared to 2 other alternatives. The impact of benefits of alternative 3 includes increasing spectrum requirements, frequency spectrum structuring, the need for legal certainty and equality of the process of transferring frequency spectrum.
\end{abstract}

\section{Introduction}

Regulation plays an important role in the telecommunications business. There are many regulatory aspects that influence the growth of broadband mobile telecommunications business such as the availability of frequency spectrum, tariffs, interconnection, content, and numbering [1]. Cellular telecommunications regulations have given birth to many cellular operators operating in Indonesia, giving rise to a tight competition climate. The growing number of cellular users as well as the limited number of spectrums owned by operators has led to a decline in service quality. The operator has to have a wide spectrum to provide good services to users and to serve a large system capacity, large number of base

\footnotetext{
* Corresponding author: gunawan@eng.ui.ac.id
} 
station systems (BTS) to cover a wide service area, and as well as the latest technology to provide services with efficiency levels spectrum and good service quality. Therefore, the operators are trying to get a larger allocation of frequency spectrum.

The use of radio frequency spectrum in Indonesia must obtain permission from the Minister of Communication and Information in the form of radio station permits. The secondary market frequency spectrum policy in Indonesia has not been implemented. Even in Government Regulation (PP) number 53/2000 in Article 25 it has been stated explicitly that holders of radio frequency allocations cannot transfer radio frequency allocations that have been obtained to other parties, unless there is approval from the Minister [2]. Basically, the frequency spectrum belongs to the government. The telecommunications operator is given the right to use the frequency spectrum with the time frame of the permits regulated in PP 53/2000 for 10 years or 5 years and can be extended with permission from the Minister. In addition, to increase the frequency spectrum utilization and avoid the practice of brokering, the Ministry of Communication and Information Technology since 2001 has implemented a modern license to the operator [3]. Modern license is a license given to an operator accompanied by a written network development commitment that must be carried out.

To avoid the frequency spectrum control monopoly through the process of acquisition or merger or consolidation between operators, the government has banned monopolistic practices regulated by Law Number 5 of 1999 concerning Prohibition of Monopolistic Practices and Unfair Business Competition [4], Law Number 36 of 1999 concerning Telecommunications [5], Law 40/2007 concerning Limited Liability Companies [6], and Law 25/2007 concerning Investment [7]. Takeover or transfer of frequencies from one operator to the operator through an auction or a beautiful contest is controlled and determined by the minister of communication and information. In this case, the role and domination of the government is very large. Secondary markets are not permitted yet in Indonesia, even in the takeover or transfer of frequency in practice it is identical to the secondary market. This can be seen from several cases that have occurred and can be classified as secondary market activities in the frequency spectrum in Indonesia, including the merger of PT. Indosat, PT. Satelindo, PT. IM3 and PT. Bimagraha; XL Axiata national roaming cooperation with Axis; cooperation between Mobile- 8 and Smart Telecom; network sharing or MVNO cooperation; and the merger of XL with Axis [8] - [9]. The transfer of the frequency spectrum from one operator to another in practice does not get the same approach from the government in an effort to avoid monopolies, maintain a competitive climate, and optimize spectrum values. There are operators who get additional frequencies accompanied by divestments but there are operators who get additional frequencies without divestment.

On the other hand, the application of a pure secondary market that has been carried out by the United Kingdom, the United States, Australia, New Zealand and Guatemala has been proven to create a healthy competition climate, increase the economic value of the spectrum, provide certainty of telecommunications business law, reduce government dominance, and give equal treatment to all parties [10 - 13]. To ensure legal certainty and equal treatment in the implementation of the secondary market, the government makes strict rules to protect interference with the next operator and maintains maximum emission level to avoid outband interference for all operators. The guarantee of business law certainty in the implementation of secondary markets makes the frequency spectrum trade receive the attention of many operators.

Therefore, it is very interesting to analyze the application of the secondary frequency spectrum market in Indonesia. There are 3 alternatives of the secondary market spectrum policy that will be evaluated, namely alternatives 1,2 , and 3 . To get good policy results, then in this study an approach of regulatory impact analysis (RIA) will be conducted. To 
assess the 3 alternative policies, cost-based analysis (CBA) is based on plus minus implication (PMI). Whereas to decide the best policy alternative, multi-criteria analysis (MCA) evaluation is used. From the results of the CBA based on PMI approach, an alternative 1 has score $=-16$ is obtained, alternative $2=4$ and alternative value $3=22$. With an MCA, the alternative 1 has score $=206$, alternative $2=250$, and alternative $3=321$. It is seen that with BCA based on PMI and MCA obtained the highest score achieved by alternative 3. The impact of alternative benefits 3 includes increasing spectrum requirements, frequency spectrum structuring that continues to experience constraints and obstacles, and the need for legal certainty and equality of the process of transferring a clear frequency spectrum

\section{Secondary market spectrums based on RIA}

In order to ensure that secondary market spectrum regulation is indispensable to the public interest, encouraging an evidence-based approach and ensuring that all practical options for addressing the problem have been considered and providing the highest benefits that exceed the costs incurred, the RIA approach is used. As a process, the implementation of the RIA method is carried out through various stages, namely:

a. Identification and analysis of problems related to policies

According to Government Regulation 53/2000, it is stated that holders of frequency allocation cannot be transferred to other parties, unless there is approval from the Minister. This is supported by different treatments in granting frequency spectrum usage rights when there is a merger or acquisition of an operator's ownership.

b. Setting goals

The government's secondary market spectrum policy aims to streamline the use of frequency spectrum by operators, ensure equality and a clear process in transferring the license to use the frequency spectrum, disclosure of information on the use of frequency spectrum, supervision and strict sanctions.

c. Development of various policy options / alternatives

There are 3 proposed alternative formulations of the secondary market spectrum policy, namely: alternative 1 which keep with the current conditions, does nothing, alternative 2 implements a secondary market with a direct trade mechanism, and alternative 3 is to implement a secondary market with a broker mechanism supervised by an independent supervisory body.

d. Assessment of alternative policy choices

Three alternatives for the preparation of the secondary market spectrum policy, the feasibility of the aspects of benefits and costs is proposed called as cost based analysis (CBA). Aspects of benefits include both direct and indirect regulators, operators, and users. While the cost aspect includes the cost of the selection process, buying and selling, controlling, operating and using the frequency spectrum which will be the obligation of the licensee. One effective method to be applied in CBA is plus-minus implication (PMI).

e. Selection of the best policy

To get a policy selection of the secondary market spectrum application, a multiple criteria analysis (MCA) approach is used. The MCA shows all the criterias that are decisive in formulating secondary market policy objectives, given weighting for each criterion and given an assessment.

\section{Results and discussions}


To be able to decide on the best policy alternative, an evaluation is done using CBA bsed PMI. Whereas the selection of the best policy alternatives is carried out with an MCA that involves all the factors that show the achievement of the policy objectives compiled, Table 1 shows CBA based PMI the proposed alternatives 1, 2 and 3. It can be seen from Table 1, an alternative 1 gets score $=-16$, alternative $2=4$, and alternative $3=22$. This means that alternative 3 provides a higher (plus) benefit than alternatives 1 and 2 . It is indicated that the all criterias at alternative 3 get score 1 as beneficial.

Table 1. CBA based pmi of the proposed alternative 1,2, and 3

\begin{tabular}{|c|c|c|c|c|c|c|c|c|c|}
\hline \multirow[t]{2}{*}{ Stakeholder } & \multirow[t]{2}{*}{ No } & \multirow[t]{2}{*}{ Plus } & \multicolumn{3}{|c|}{$\begin{array}{c}+1 /-1 \\
\text { Alternative }\end{array}$} & \multirow[t]{2}{*}{ Minus } & \multicolumn{3}{|c|}{$\begin{array}{c}+1 /-1 \\
\text { Alternative }\end{array}$} \\
\hline & & & 1 & 2 & 3 & & 1 & 2 & 3 \\
\hline \multirow[t]{4}{*}{ Regulator } & 1 & Frequency spectrum arrangement & 1 & -1 & 1 & $\begin{array}{l}\text { Regulatory } \\
\text { socialization } \\
\text { costs }\end{array}$ & -1 & 1 & 1 \\
\hline & 2 & Frequency spectrum control & 1 & -1 & 1 & $\begin{array}{l}\text { Monitoring and } \\
\text { evaluation costs }\end{array}$ & -1 & 1 & 1 \\
\hline & 3 & Regulatory arrangement & -1 & -1 & 1 & & & & \\
\hline & 4 & Economic value of frequency band & -1 & 1 & 1 & & & & \\
\hline \multirow[t]{7}{*}{ Operator } & 1 & $\begin{array}{l}\text { The need of additional frequency } \\
\text { spectrum }\end{array}$ & -1 & -1 & 1 & Refarming costs & -1 & 1 & 1 \\
\hline & 2 & Use of frequency spectrum & -1 & 1 & 1 & OPEX & 1 & -1 & 1 \\
\hline & 3 & Competision & -1 & -1 & 1 & Licence Fee & -1 & 1 & 1 \\
\hline & 4 & Equality of & -1 & 1 & 1 & & & & \\
\hline & 5 & $\begin{array}{l}\text { Legal certainty of the right to } \\
\text { transfer the use of frequency } \\
\text { spectrum }\end{array}$ & -1 & 1 & 1 & & & & \\
\hline & 6 & $\begin{array}{l}\text { Secondary market frequency } \\
\text { spectrum }\end{array}$ & -1 & 1 & 1 & & & & \\
\hline & 7 & $\begin{array}{l}\text { Information disclosure of the use } \\
\text { of frequency spectrum }\end{array}$ & -1 & -1 & 1 & & & & \\
\hline \multirow[t]{6}{*}{ User } & 1 & Network access & -1 & 1 & 1 & & & & \\
\hline & 2 & Choice of products and services & -1 & 1 & 1 & & & & \\
\hline & 3 & Producs and services price & -1 & 1 & 1 & & & & \\
\hline & 4 & Quality of Service & -1 & -1 & 1 & & & & \\
\hline & 5 & Technology change & -1 & 1 & 1 & & & & \\
\hline & 6 & Customer protection & -1 & -1 & 1 & & & & \\
\hline \multicolumn{3}{|l|}{ Subtotal } & -13 & 1 & 17 & & -3 & 3 & 5 \\
\hline \multicolumn{3}{|l|}{ Total } & & & & & -16 & 4 & 22 \\
\hline
\end{tabular}

The CBA based on PMI evaluation is insufficient to decide that alternative 3 provides many benefits. Therefore, to strengthen in deciding the best alternative proposed, the three alternatives were evaluated and analyzed by the MCA. Table 2 shows the comparison of the results of MCA for alternatives 1, 2, and 3. From Table 2 shows the alternative value $1=$ 206 , alternative $2=250$, and alternative $3=321$. This means that the factors in alternative 3 strongly support the purpose of applying the market Secondary frequency spectrum in Indonesia and have a beneficial effect. The impact of alternative benefits 3 includes increasing spectrum requirements, frequency spectrum structuring that continues to experience constraints and obstacles, and the need for legal certainty and equality of the process of transferring a clear frequency spectrum. By implementing alternative policy 3 , it is expected that constraints on spectrum requirements can be overcome by configuring permits based on geographic, bandwidth and time, where it can provide flexibility in radio frequency spectrum management, but still based on certain parameters through an 
independent oversight body evaluation process. It aims to be able to provide legal certainty and equality in the transfer of the radio frequency spectrum.

Table 2. MCA of the Proposed Alternative 1, 2, and 3

\begin{tabular}{|c|c|c|c|c|c|c|c|c|}
\hline \multirow{2}{*}{ No } & \multirow{2}{*}{ Indikator } & \multirow{2}{*}{ Weight } & \multicolumn{2}{|c|}{ Alternative 1 } & \multicolumn{2}{|c|}{ Alternative 2 } & \multicolumn{2}{|c|}{ Alternative 3} \\
\hline & & & Score & Total & Score & Total & Score & Total \\
\hline $\mathbf{A}$ & Regulator & & & & & & & \\
\hline 1 & $\begin{array}{l}\text { Frequency spectrum } \\
\text { arrangement }\end{array}$ & 5 & 4 & 20 & 2 & 10 & 3 & 15 \\
\hline 2 & Frequency spectrum control & 5 & 4 & 20 & 2 & 10 & 3 & 15 \\
\hline 3 & Regulatory arrangement & 4 & 2 & 8 & 3 & 12 & 5 & 20 \\
\hline 4 & $\begin{array}{l}\text { Economic value of frequency } \\
\text { band }\end{array}$ & 5 & 3 & 15 & 3 & 15 & 4 & 20 \\
\hline 5 & Regulatory socialization costs & 2 & 3 & 6 & 3 & 6 & 3 & 6 \\
\hline 6 & $\begin{array}{l}\text { Monitoring and evaluation } \\
\text { costs }\end{array}$ & 2 & 2 & 4 & 3 & 6 & 4 & 8 \\
\hline & Subtotal & & & 73 & & 59 & & 84 \\
\hline $\mathbf{B}$ & Operator & & & & & & & \\
\hline 1 & $\begin{array}{l}\text { The need of additional } \\
\text { frequency spectrum }\end{array}$ & 4 & 3 & 12 & 2 & 8 & 4 & 16 \\
\hline 2 & Use of frequency spectrum & 5 & 2 & 10 & 3 & 15 & 4 & 20 \\
\hline 3 & Competision & 5 & 2 & 10 & 3 & 15 & 4 & 20 \\
\hline 4 & $\begin{array}{l}\text { Equality of transfer frequency } \\
\text { spectrum }\end{array}$ & 5 & 1 & 5 & 3 & 15 & 4 & 20 \\
\hline 5 & $\begin{array}{l}\text { Legal certainty of the right to } \\
\text { transfer the use of frequency } \\
\text { spectrum }\end{array}$ & 5 & 3 & 15 & 3 & 15 & 3 & 15 \\
\hline 6 & Refarming costs & 2 & 2 & 4 & 3 & 6 & 4 & 8 \\
\hline 7 & OPEX & 2 & 4 & 8 & 2 & 4 & 3 & 6 \\
\hline 8 & Licence Fee & 2 & 2 & 4 & 3 & 6 & 3 & 6 \\
\hline 9 & Secondary market spectrum & 5 & 1 & 5 & 4 & 20 & 4 & 20 \\
\hline 10 & $\begin{array}{l}\text { Secondary market spectrum } \\
\text { benefits }\end{array}$ & 4 & 3 & 12 & 3 & 12 & 4 & 16 \\
\hline & Subtotal & & & 85 & & 116 & & 147 \\
\hline $\mathbf{C}$ & User & & & & & & & \\
\hline 1 & Network access & 3 & 2 & 6 & 3 & 9 & 4 & 12 \\
\hline 2 & $\begin{array}{l}\text { Choice of products and } \\
\text { services }\end{array}$ & 3 & 2 & 6 & 4 & 12 & 3 & 9 \\
\hline 3 & Products and services price & 3 & 2 & 6 & 3 & 9 & 3 & 9 \\
\hline 4 & Quality of service & 5 & 2 & 10 & 3 & 15 & 4 & 20 \\
\hline 5 & Technology change & 5 & 1 & 5 & 5 & 25 & 3 & 15 \\
\hline 6 & Customer protection & 5 & 3 & 15 & 1 & 5 & 5 & 25 \\
\hline & Subtotal & & & 48 & & 75 & & 90 \\
\hline & Total & & & 206 & & 250 & & 321 \\
\hline
\end{tabular}

\section{Conclusions}

In this study secondary market spectrum policy has been analyzed with the RIA approach for the three proposed alternatives. Three alternatives are determined, calculated and compared between the benefits and costs of each alternative using CBA based on PMI. 
It is shown that alternative 1 had scores $=-16$, scores for alternatives $2=4$ and scores for alternatives $3=22$. By using MCA, a score of alternative $1=206$, score for alternative $2=$ 250 and score for alternative $3=321$. Based on the results of the analysis using RIA to 3 alternative choices, alternative 3 is obtained which has benefits that are greater than the costs (losses) incurred. This can be seen from the results that impacts related to the increasing spectrum requirements, frequency spectrum structuring that continues to experience constraints and obstacles, and the need for legal certainty and equality of the process of transferring a clear frequency spectrum. By implementing alternative policy 3 , it is expected that the constraints of spectrum requirements can be overcome by configuring permits based on geographic, bandwidth and specific time, where it can provide flexibility in the arrangement of radio frequency spectrum, but still based on certain parameters through the supervisory body evaluation process independent.

\section{Aknowledgment}

The authors would like to sincerely acknowledge Universitas Indonesia as this work has been supported by the DRPM Research Grant for PITTA 2018 program No. 2445/UN2.R3.1/HKP 05.00/2018

\section{References}

1. B. Elian, Analysis of Radio Frequency Spectrum Needs for Indonesian Wireless Broadband Radio Communication in 2010-2025, Thesis, Universitas Indonesia (2015)

2. Republic of Indonesia, Government Regulation (PP) No. 53/2000 concerning Use of Radio Frequency Spectrum and Satellite Orbit (2000)

3. Ministry of Transportation, Decree of the Minister of Transportation No. 30/2004 concerning Amendments to the Decree of the Minister of Transportation No. 21/2001 concerning the implementation of Telecommunications (2004)

4. Republic of Indonesia, Law Number 5 of 1999 concerning Prohibition of Monopolistic Practices and Unfair Business Competition (1999)

5. Republic of Indonesia, Law of the Republic of Indonesia Number 36/1999 concerning Telecommunications (1999)

6. Republic of Indonesia, Law 40/2007 concerning Limited Liability Companies (2007)

7. Republic of Indonesia, Law 25/2007 concerning Investment (2007)

8. Ministry of Communication and Information Technology, Decree of the Minister of Communication and Information of the Republic of Indonesia Number 1192/2013 concerning Stipulation of Block Allocation of Radio Frequency Bands of Comprehensive Arrangement of 2.1 GHz Radio Frequency Bands (2013)

9. Ministry of Communication and Information, Regulation of the Minister of Communication and Information of the Republic of Indonesia Number 4/2015 concerning Operational Provisions and Procedures for Licensing to Use Radio Frequency Spectrum (2015)

10. Electronic Communications Committee (ECC), Refarming and Secondary Trading in a Changing Radiocommunication World, in the European Conference of Postal and Telecommunications Administrations (2002).

11. M. Barrie, S. Delaere and P. Ballon, Classification of business scenarios for spectrum sensing, in Proc. PIMRC, 2010 IEEE 21st International Symposium on (pp. 26262631) (2010) 
12. S. Bridge, The secondary spectrum market: a primary licensing and leasing, Florida: Spectrum Bridge, Inc., (2009)

13. J. W. Mayo and S. Wallsten, Enabling efficient wireless communications: the role of secondary spektrum markets, Washington DC: Technology Policy Institute, pp. 1-30 (2009) 